\section{Commentary: Strength at the cutting edge}

\author{
Song Wan, MD, FRCS, ${ }^{a}$ and Jun Liu, $\mathrm{PhD}^{\mathrm{b}}$
}

Implantation of artificial neochordae made of expanded polytetrafluoroethylene (ePTFE) has been a mainstay technology in mitral valve repair. Determining the proper length of a neochord intraoperatively, however, is not always straightforward for surgeon. Occasionally, the dynamic changes that occur during cardiac cycles following the release of the aortic crossclamp can unexpectedly impair a "perfect fit" neochord that was measured on an arrested heart and tested by saline injection through the mitral valve to fill the left ventricle. That multiple methods have been developed to address this neochordal-measurement issue reflects its intrinsic complexity as well as the lack of an "ideal" strategy to overcome the multifarious difficulties involved in neochordae implantation.

In this regard, Sotolongo and colleagues' adjustable neochordae implantation technique ${ }^{1}$ is definitely auspicious. It proves that innovation is always born of necessity, as this ingenious new method can apparently facilitate intraoperative neochordal adjustment. Sotolongo and colleagues have successfully applied this technique in 22 patients (the majority through a minimally invasive approach) and have achieved excellent short-term outcomes.

Nonetheless, the strength of any innovation can often be defined by its "weakest link." After a brief analysis, we must conclude that the CV-5 type of ePTFE sutures chosen by Sotolongo and colleagues might not be adequate. In the new adjustable technique, 2 arms of the ePTFE sutures are passed through the corresponding papillary muscle, then

\footnotetext{
From the a Division of Cardiothoracic Surgery, Department of Surgery, The Chinese University of Hong Kong, Prince of Wales Hospital; and ${ }^{b}$ Department of Mechanical Engineering, City University of Hong Kong, Hong Kong, China.

Disclosures: The authors reported no conflicts of interest.

The Journal policy requires editors and reviewers to disclose conflicts of interest and to decline handling or reviewing manuscripts for which they may have a conflict of interest. The editors and reviewers of this article have no conflicts of interest.

Received for publication Jan 19, 2020; revisions received Jan 19, 2020; accepted for publication Feb 2, 2020; available ahead of print Feb 20, 2020.

Address for reprints: Song Wan, MD, FRCS, Division of Cardiothoracic Surgery, Department of Surgery, The Chinese University of Hong Kong, Prince of Wales Hospital, Hong Kong, China (E-mail: swan@surgery.cuhk.edu.hk).

JTCVS Techniques 2020;2:58-9

2666-2507

Copyright $(2020$ The Authors. Published by Elsevier Inc. on behalf of The American Association for Thoracic Surgery. This is an open access article under the CC BY-NCND license (http://creativecommons.org/licenses/by-nc-nd/4.0/).

https://doi.org/10.1016/j.xjtc.2020.02.008
}

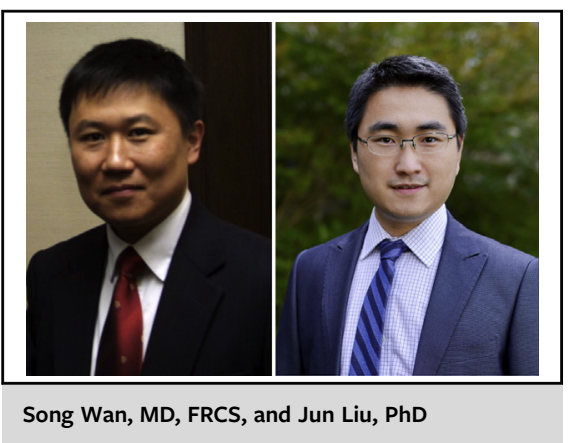

CENTRAL MESSAGE

To strengthen the potential

"weakest link" of the adjustable

neochordae implantation tech-

nique, CV4 polytetrafluoroethy-

lene sutures should be used in

preference to the originally pro-

posed $\mathrm{CV}_{5}$ sutures.

pulled toward the annular base and secured on the atrial side of the posterior mitral annulus. As illustrated in Figure 1, $A$, whereas the conventional method directly connects the edge of the mitral valve leaflet with the papillary muscle (shown as a green dashed line), the new technique uses longer neochordae (shown as red lines in Figure 1, $B)$. The increased length may increase the risk of neochordae rupture, which has been observed in transapical neochordae implantations. ${ }^{2}$ Previous studies have indicated that increased length of neochordae correlates with an escalation in stiffness. ${ }^{3}$ Change in the neochord anchoring angle may result in greater forces being exerted on the neochordae suture, as well as an increased rate of loading on the neochordae compared with the conventional fixation. ${ }^{4}$ Moreover, the adjustable arms at the annular side will unavoidably produce a side-pulling force and further increase the tension applied to the neochordae. When peak systolic blood pressure is reached, the new adjustable technique is expected to generate an effective holding force via the neochordae to reach an equilibrium state similar to that in the conventional method, where the systolic force $F_{s y s}$ is equal to the chordae holding force $F_{c o n}$ :

$$
F_{\text {sys }}=\int S B P \mathrm{ds}=F_{\text {con }}
$$

In the new adjustable technique, the tension applied on the neochordae $F_{a d j}$ can be broken down into 2 components: 

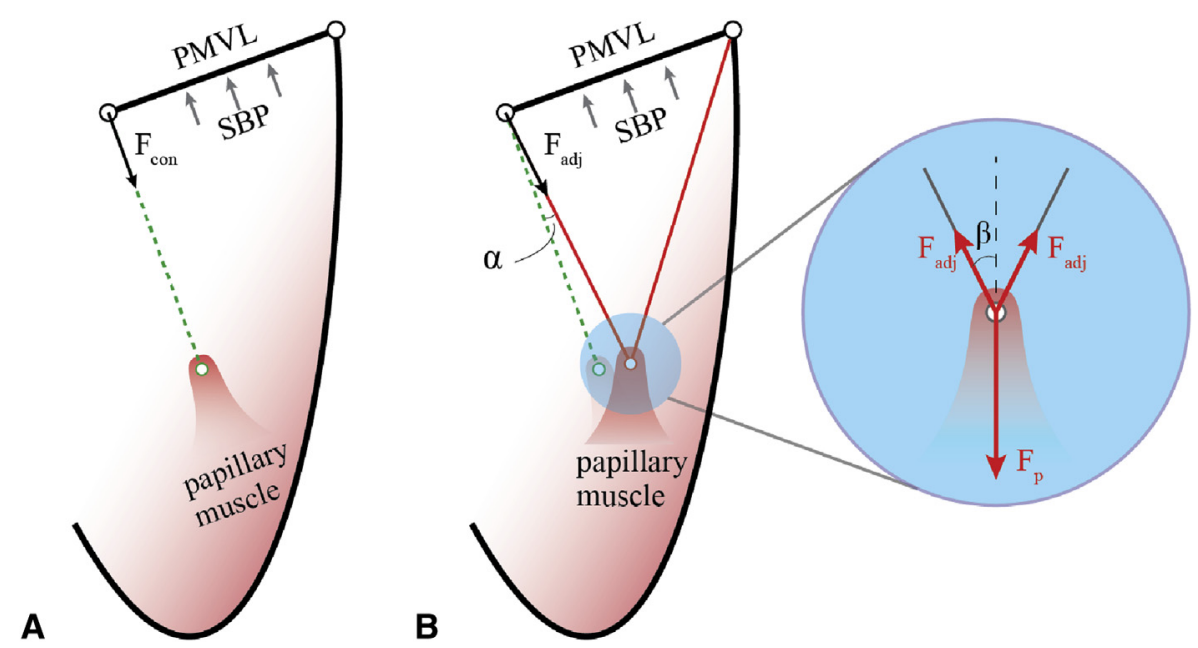

FIGURE 1. Diagram of the mechanics of the conventional and adjustable methods of neochordae implantation. A, The conventional method directly connects the PMVL and the papillary muscle with a maximum tension force $F_{c o n}$. B, In the adjustable method, longer neochords are used and the adjustable arms pull the papillary muscles sideways with increased force $\left(F_{a d j}\right)$. The forces applied to the papillary muscles $F_{p}$ are also greater than that in the conventional method. $P M V L$, Posterior mitral valve leaflet; $S B P$, systolic blood pressure.

$F_{1}=F_{\text {con }}$ along the green dashed line; and $F_{2}$ caused by the adjustable end of the neochordae. From the force analysis, we have $F_{c o n}=F_{a d j} * \cos \alpha$, where $\alpha$ is the angle between the neochordae in the adjustable method and the conventional method (see Figure 1, $B$ ). Therefore, the force applied to the neochordae in the adjustable technique is greater than that in the conventional method (ie, $F_{a d j}>F_{c o n}$ ).

When analyzing the force on the penetrating point at the papillary muscle, we further find that the force exerted on the papillary muscle $F_{p}$ is also increased. As shown in the inset of Figure $1, B$, we have $F_{p}=2 F_{a d j} \cos \beta$, where $\beta$ is equal to half of the angle between the neochord portions penetrating into and out of the papillary muscle. Based on the anatomy of the left ventricle, one can assume that $\beta$ could be less than $30^{\circ}$. Therefore, we have $\cos \beta>0.866$ and $F_{p}>1.732 F_{a d j}$. Compared with the classical method where the force applied to the papillary muscle directly equals the neochordal tension, the new technique produces a significantly increased pulling force on the papillary muscle that could increase the risk of cutting through the papillary muscle tip or causing a remodeling of papillary anatomy.

This mechanics analysis (Figure 1) is necessarily simplified and may not be accurate, given the complex anatomy of the ventricle and the mitral valve. However, it should be noted that the new technique inevitably uses longer ePTFE neochordae than the conventional method and applies increased tension to the neochordae. Considering the altered mechanics associated with the adjustable technique, we recommend use of neochordae with increased strength to reduce the risk of the neochordal rupture.

To summarize, in applying the new adjustable neochordae implantation technique, the sutures chosen should probably be CV-4 ePTFE, rather than the originally proposed CV-5. Although Sotolongo and colleagues deserve congratulations for their innovative modification, we eagerly await their long-term follow-up data.

\section{References}

1. Sotolongo A, Mahmood SUB, Vaccaro B, Geirsson A. Mitral valve repair using adjustable posterior leaflet neochords. J Thorac Cardiovasc Surg Tech. 2020;2: $50-4$.

2. Grinberg D, Adamou Nouhou K, Pozzi M, Obadia J-F. Artificial mitral chordae: when length matters. J Thorac Cardiovasc Surg. 2019;157:e23-5.

3. Caimmi PP, Sabbatini M, Fusaro L, Borrone A, Cannas M. A study of the mechanical properties of ePTFE suture used as artificial mitral chordae. J Card Surg. 2016;31:498-502.

4. Imbrie-Moore AM, Paulsen MJ, Thakore AD, Wang H, Hironaka CE, Lucian HJ, et al. Ex vivo biomechanical study of apical versus papillary neochord anchoring for mitral regurgitation. Ann Thorac Surg. 2019;108:90-7. 